\title{
Separation of brewer pellets in a vibratory-centrifugal centrifuge
}

\author{
Vladislav Nikolayev ${ }^{1}$, Marat Akhmetvaliyev ${ }^{1}$, Alexandr Gritsenko ${ }^{1,2}$ and Vladimir Shepelev ${ }^{2,3^{*}}$ and Ildus Gimaltdinov ${ }^{4}$ \\ ${ }^{1}$ South Ural State Agrarian University, Department of Machine-Tractor Fleet Operation, Troitsk, 457100, Russia \\ ${ }^{2}$ South Ural State University, Department of Automobile Transport, Chelyabinsk, 454080, Russia \\ ${ }^{3}$ Silkway International University, Shymkent, 160000, Kazakhstan \\ ${ }^{4}$ Kazan State Agrarian University, Kazan, 420015, Russia
}

\begin{abstract}
The article reflects the process of dehydration of brewer pellets, as one of the ways to solve the problem of their utilization in order to obtain a highly concentrated feed for farm animals, which is an urgent task. The purpose of the study is to substantiate the interrelation between the technological and physical properties of the brewer pellets during the separation of brewer pellets into dense and liquid fractions in a continuous vibratory-centrifugal centrifuge and its main design and operating parameters. As a result of the research with the analytical method, process and physical properties of brewer pellets are determined when they are interacting with the perforated rotor blades of a vibratory-centrifugal centrifuge. The equations for the yield of the liquid fraction of brewer pellets through the rectilinear and curvilinear rotor blades are obtained, indicating the interrelation between process and physical properties of brewer pellets, which are necessary for determining the rational basic parameters of the proposed vibratory-centrifugal centrifuge.
\end{abstract}

\section{Introduction}

Increasing the productivity of animals and poultry is one of the main tasks of animal husbandry, which is implemented through the use of new types of feed and introduction of advanced resource-saving machines and technologies for their high-quality production. This topic is relevant and is considered in many works [1,2]. Many scientists [3-5] considered this problem in their studies. A study [6] presented the current state of knowledge on the composition of phenolic compounds in beer and brewing raw materials with a special focus on their fate from raw materials throughout the malting and brewing process to the final beer.

At present, the problem of selling beer waste is very acute because of insufficient financial resources in agricultural enterprises. Therefore, beer mills often simply get rid of the nutritionally valuable brewer pellets due to their continuous production, and thus both beer mills themselves and agricultural enterprises bear losses, which ultimately leads to a reduction in agricultural production. One way to solve this problem can be dehydration of brewer pellets, followed by drying or pressing, which will allow storing dry food for a long time before it is sold. The topic of beer granules and everything connected with them is analysed in several works [6-10].

However, the implementation of this promising direction is constrained due to the lack of knowledge and the lack of high-tech equipment. The complexity and versatility of the brewer pellet processing requires the combination of modern scientific and technical achievements in various fields of the agro-industrial complex and the knowledge of highly qualified specialists.

Based on the above, it can be concluded that the problem of utilization of brewer pellets, in order to obtain a highly concentrated feed for farm animals, remains relevant today.

The purpose of the study is to substantiate the interrelation between process and physical properties of brewer pellets during the separation of brewer pellets into dense and liquid fractions in a continuous vibratorycentrifugal centrifuge and the main design and operating parameters of such centrifuge.

\section{Materials and Methods}

To achieve the goal using the analysis of centrifuge designs at the Department of the Livestock Production Technology and Engineering and Engineering Graphics of South Ural State Agrarian University, a vibratorycentrifugal centrifuge was developed to separate brewer pellets into liquid and dense fractions (Fig. 1) [11, 12].

To substantiate the basic parameters of a blade rotor of the vibratory-centrifugal centrifuge, let us represent the scheme of the separation of brewer pellets into liquid and the dense fractions (Fig. 2). The scheme shows that perforated rectilinear and curvilinear blades are installed in the alternating order, making the axial vibration in a vertical plane perpendicular to the plane of during the rotation of the rotor [12-14]. 

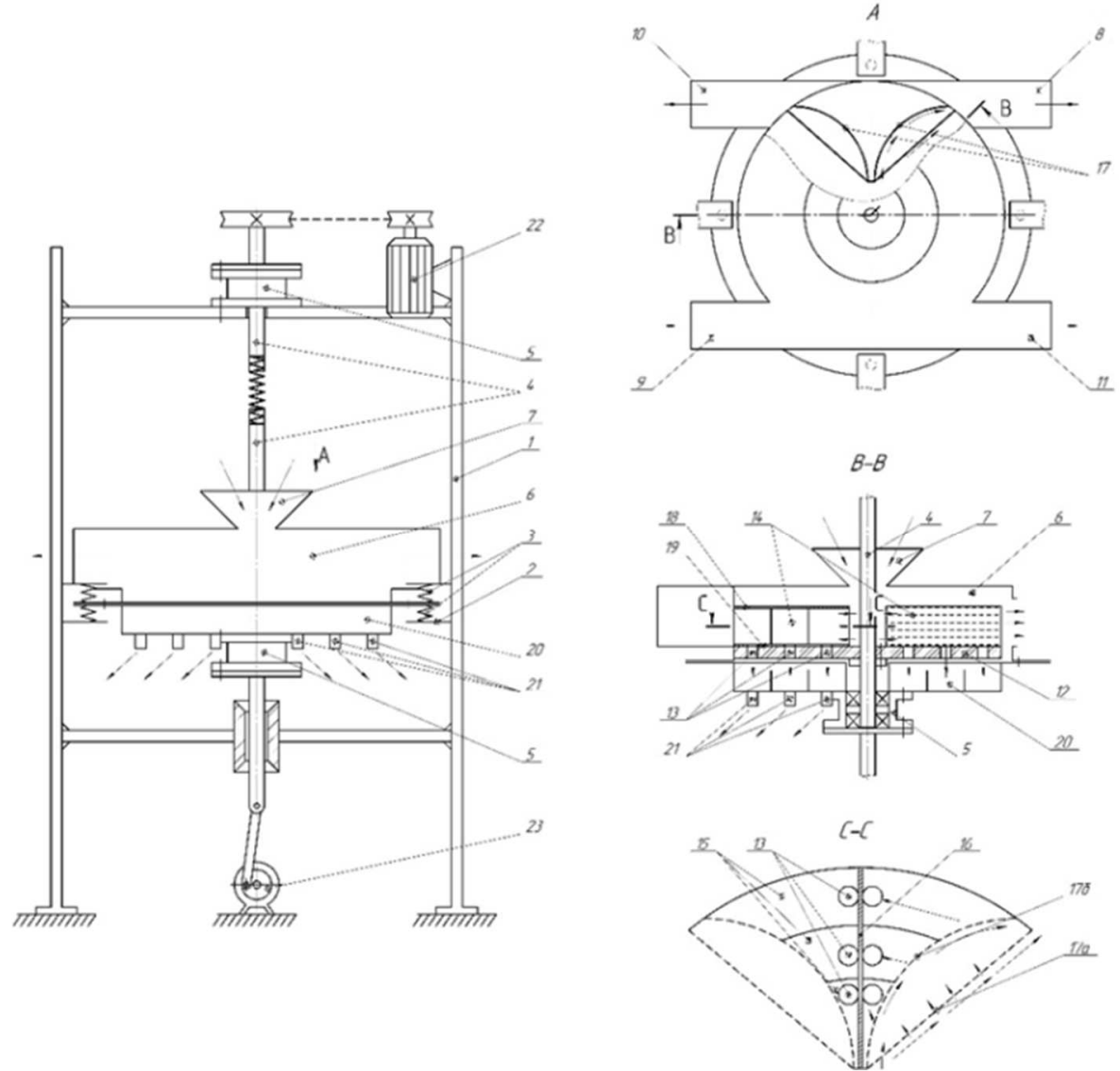

Fig. 1. Centrifuge for the separation of brewer pellets: 1 - frame; 2 - support; 3 - spring; 4 - shaft; 5 - bearing support; 6 - case; 7 - inlet nozzle; 8, 9, 10, 11 - outlet nozzles; 12 - rotor disc;13 - the holes of the disk; 14 - unit of blades; 15 - sectors; 16 - plate;17a -rectilinear perforated screen; 17b - curved perforated screen; 18 , 19 - upper and lower sectors of the blade unit circle; 20 - radial-sector bottom, 21 - tubes, 22 , 23 actuators.

As can be seen in the scheme, the initial mass is first supplied to a straight blade with rectangular openings up to $2 \mathrm{~mm}$ high, on which the remaining particles of the most part of the dense fraction are retained and move to their ejection from the centrifuge in the direction towards the periphery of the rotor due to centrifugal forces, and the liquid fraction with the particles enter the surface of the curved blade and there is a final dehydration of brewer pellets. Thus, a differentiation (distribution) of the initial mass of the liquid stream in the process of the separation of brewer pellets into liquid and dense fractions takes place and on that basis the equi-thickened filtered material layer over the entire surface of the rotating rotor blades with axial vibrations is ensured [15].

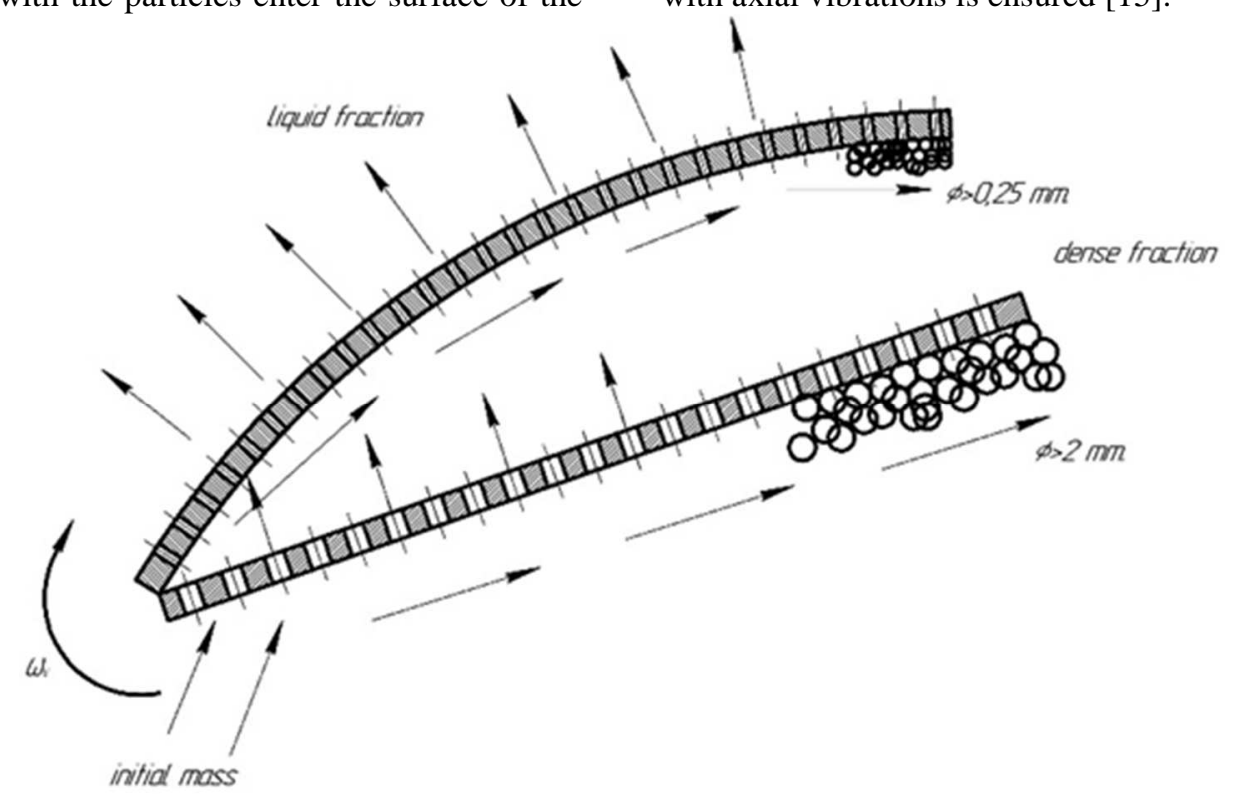

Fig. 2. The scheme of the separation of the flow of brewer pellets on the blades of the vibrating rotor.

\footnotetext{
* Corresponding author: shepelevvd@ susu.ru
} 
During the preliminary experiments, all values of the kinematic parameters were fixed at the zero level except for one, which made it possible to reveal the nature of its effect on the process of vibratory-centrifugal filtration of liquid brewer pellets [16].

In order to more accurately assess the effect of each factor on the primary sludge dewatering in the rotor blade of the vibratory-centrifugal centrifuge, a four-factor experiment on 3 different levels was planned (Table 1).

Table 1. Factors, intervals and levels of variation.

\begin{tabular}{|c|c|c|c|c|c|c|}
\hline \multicolumn{2}{|c|}{\begin{tabular}{|c|}
$\begin{array}{c}\text { Factor } \\
\text { designation }\end{array}$ \\
\end{tabular}} & \multirow{2}{*}{$\begin{array}{l}\text { Factor } \\
\text { name }\end{array}$} & \multicolumn{3}{|c|}{ Level of variation } & \multirow{2}{*}{$\begin{array}{c}\text { Step of } \\
\text { variation }\end{array}$} \\
\hline Code & $N_{a t .}$ & & $\begin{array}{c}\text { Upper } \\
-1\end{array}$ & Opt. & $\begin{array}{c}\text { Lower } \\
+1\end{array}$ & \\
\hline$X_{1}$ & $\omega_{s}, \mathrm{c}^{-1}$ & $\begin{array}{l}\text { Rotor } \\
\text { speed }\end{array}$ & 41.89 & 52.36 & 62.83 & 10.47 \\
\hline$X_{2}$ & $A_{o}, \mathrm{M}$ & $\begin{array}{l}\text { Rotor } \\
\text { ampli- } \\
\text { tude } \\
\text { oscillati } \\
\text { ons }\end{array}$ & 0.002 & 0.004 & 0.006 & 0.002 \\
\hline$X_{3}$ & $\omega_{o}, \mathrm{c}^{-1}$ & $\begin{array}{l}\text { Rotor } \\
\text { rotation } \\
\text { frequ- } \\
\text { ency } \\
\end{array}$ & 41.89 & 62.83 & 83.77 & 20.94 \\
\hline$X_{4}$ & $S_{f s, \mathrm{M}^{2}}$ & $\begin{array}{l}\text { Area of } \\
\text { the free } \\
\text { feed } \\
\text { section } \\
\text { of the } \\
\text { feeding } \\
\text { of } \\
\text { brewer } \\
\text { pellets }\end{array}$ & 0.00064 & 0.00072 & 0.0008 & 0.00008 \\
\hline
\end{tabular}

$$
\begin{gathered}
\omega_{s}=10.47 \cdot X_{1}+52.36 \\
A_{o}=0.002 \cdot X_{2}+0.004 \\
\omega_{o}=20.94 \cdot X_{3}+62.83 \\
S_{f s}=0.00008 \cdot X_{4}+0.00072 \\
y=b_{0}+\sum_{i=1}^{K} b_{i} x_{i} \sum_{i=1}^{K-1} \sum_{j>i}^{K} b_{i j} x_{i} x_{j}+\sum_{1}^{K} b_{i i} x_{i}^{2}
\end{gathered}
$$

where: $b_{0}, b_{i}, b_{i j}, b_{i i}$ are the coefficients of the polynomial; $x_{i}, y$ are the values of the given factors in the encoded form (Table 1).

The planning matrix consists of 25 experiments with triplicate repetition. In this case, according to the BIB scheme, each block contains 6 small blocks (4 experiments in each) and 3 separate experiments at the zero level of factors.

\section{Results and Discussion}

As a result of the research using the analytical method, the technological and physical properties of brewer pellets are determined when interacting with the perforated rotor blades of a vibratory-centrifugal centrifuge.

Humidity is one of the most important characteristics of any feed, the content of which impacts not only its aggregate state and structural and mechanical properties, but also the nature of interaction with the working bodies of machines.

The humidity content of the initial brewer pellets is determined by the formula [17]:

$$
W_{i}=\frac{m_{i}-m_{s}}{m_{i}} \cdot 100 \%=\frac{m_{l}}{m_{i}} \cdot 100 \%
$$

where $m_{i}$ is the initial mass of brewer pellets, $\mathrm{kg} ; m_{s}$ is the mass of the dry sludge, $\mathrm{kg} ; m_{l}$ is the mass of the liquid component, $\mathrm{kg}$.

The humidity content of brewer pellets sludge:

$$
W_{o}=\frac{m_{l}^{s l}}{m^{s l}} \cdot 100 \%
$$

where $m_{l}^{s l}$ is the mass of the liquid component in the sludge, $\mathrm{kg} ; m^{s l}$ is the mass of the sludge, $\mathrm{kg}$.

The mass of the liquid phase in brewer pellets:

$$
m_{l}=\frac{m_{i} \cdot W_{i}}{100 \%}
$$

The mass of the dry component in brewer pellets:

$$
m_{s}=\frac{100 \%-W_{i}}{W_{i}} \cdot m_{l}
$$

The content of the liquid phase and the dry component in brewer pellets passing through the rectilinear rotor blade of the proposed installation:

$$
\begin{aligned}
m_{l}^{s l}=m_{s l}-m_{1}^{s l} \\
m_{l}^{p r}=m_{s}-K_{g} \cdot m_{s}=m_{s} \cdot\left(1-K_{l}^{p r}\right)
\end{aligned}
$$

where $K_{l}^{p r}$ is the granulometric coefficient, which is the ratio of particles of brewer pellets on the rectilinear and curved blades.

Humidity of the sludge at the exit from the rectilinear blade:

$$
W_{l}^{p r}=\frac{m_{s l}^{p r}}{m_{l}^{p r}} \cdot 100 \%=\frac{100 \% \cdot m_{s l}^{p r}}{m_{s l}^{p r}+m_{l}^{p r}}
$$

Whence taking into account the formulas (6-12), the mass of the outlet of the liquid part of the filtrate:

$$
m_{l f}^{p r}=\frac{m_{i}\left(W_{i}+W_{l} \cdot\left(K_{l}^{p r}-\frac{100 \%-K_{l}^{p r} \cdot W_{i}}{100 \%}\right)\right)}{100 \%-W_{l}}
$$

Expressing mass through productivity:

$$
m=Q \cdot t
$$

And thus reducing the time, since the process is continuous, equation (13) can be represented in the form:

\footnotetext{
* Corresponding author: shepelevvd@ susu.ru
} 


$$
Q_{l c}^{p r}=\frac{Q_{i}\left(W_{i}+W_{l} \cdot\left(K_{l}^{p r}-\frac{100 \%-K_{l}^{p r} \cdot W_{i}}{100 \%}\right)\right)}{100 \%-W_{l}}
$$

The content of the liquid phase and the dry component in brewer pellets passing through the curved blade:

$$
\begin{aligned}
& m_{s l}^{c b}=m_{l}-m_{s l}^{p r}-m_{c b}^{p r} \\
& m_{l c}^{c b}=m_{c}-m_{l c}^{p r}-m_{c l}^{c b}
\end{aligned}
$$

Humidity of the sludge at the outlet from the curved blade:

$$
W_{l}^{c b}=\frac{m_{s l}^{c b}}{m_{l}^{c b}} \cdot 100 \%=\frac{100 \% \cdot m_{s l}^{c b}}{m_{s l}^{c b}+m_{l}^{c b}}
$$

Whence taking into account the formulas (6-18), the mass of the outlet of the liquid part of the filtrate:

$$
m_{l c}^{c b}=\frac{m_{l c}^{p r} \cdot\left(100 \%-W_{l}^{c b}\right)-m_{i} \cdot K_{l} \cdot W_{l}^{c b} \cdot\left(1-\frac{W_{i}}{100 \%}\right)}{\left(100 \%-W_{l}^{c b}\right)-\frac{W_{l}^{c b} \cdot B_{f}}{\rho_{d}}}
$$

where $B_{f}$ is the content of suspended matter in the filtrate, $\mathrm{kg} / \mathrm{l} ; \rho_{d}$ is the filtrate density, $\mathrm{kg} / \mathrm{l}$.

Taking into account Eq. (13) and Eq. (14), let us represent Eq. (20) in the form:

$\left.Q_{l}^{c b}=\frac{\left(\frac{\left(100 \%-W_{l c}^{c b}\left(W_{i}+W_{l c} \cdot\left(K_{l}^{p r}-\frac{100 \%-K_{l}^{p r} \cdot W_{i}}{100 \%}\right)\right)\right.}{100 \%-W_{l c}}-K_{l} \cdot W_{l c}^{c b} \cdot\left(1-\frac{W_{i}}{100 \%}\right)\right.}{\left(100 \%-W_{l}^{c b}\right)-\frac{W_{l}^{c b} \cdot B_{f}}{\rho_{d}}}\right)$

Eq. (15) and Eq. (20) indicate the interrelation between technological and physical properties of brewer pellets, which are necessary for determining the rational basic parameters of the proposed vibratory-centrifugal centrifuge.

As a result of experimental studies, using the methods of mathematical statistics, a regression equation was obtained that characterizes the change in the humidity content $\mathrm{W}$ from the basic constructive-regime parameters $\omega_{s}, A_{o}, \omega_{o}, S_{f s}$ adequately describing the process of sludge dewatering in the rotor of a vibratory-centrifugal centrifuge.

The regression equation has the form:

$$
\begin{aligned}
& W\left(\omega_{s}, A_{o}, \omega_{o}, S_{f s}\right)=176.537-0.278 \omega_{s}-8.338 A_{o}- \\
& -0.016 S_{f s}+2.952 \cdot 10^{-4} \omega_{s}^{2}+0.836 A_{o}^{2}+0.857 \cdot 10^{-4} \omega_{s}^{2}+ \\
& +0.059 \cdot 10^{-4} S_{s f}^{2}+0.117 \cdot 10^{-2} \omega_{s} A_{o}-0.223 \cdot 10^{-4} \omega_{s} \omega_{o}+ \\
& +0.033 \cdot 10^{-4} \omega_{s} S_{f s}-0.035 \cdot 10^{-2} A_{o} \omega_{o}+ \\
& +0.097 \cdot 10^{-2} A_{o} S_{f s}-0.7 \cdot 10^{-6} \omega_{o} S_{f s}
\end{aligned}
$$

From the basic equation of regression, equations (8-13) were obtained and response surfaces were constructed from them [18].

The change in humidity from the rotor speed and rotor oscillations amplitude of the centrifuge:

$$
\begin{aligned}
& W 1\left(\omega_{s}, A_{o}\right)=57.238+1.23 \omega_{s}-0.205 A_{o}+ \\
& +2.952 \omega_{s}^{2}+3.346 A_{o}^{2}+0.235 \omega_{s} A_{o}
\end{aligned}
$$

The change in humidity from the rotor speed and rotor frequency:

$$
\begin{aligned}
& W 2\left(\omega_{s}, \omega_{o}\right)=57.238+1.23 \omega_{s}-0.983 \omega_{o}+ \\
& +2.952 \omega_{s}^{2}+3.429 \omega_{o}^{2}+0.447 \omega_{s} \omega_{o}
\end{aligned}
$$

The change in humidity from the rotor speed and the area of the free feed section.

$$
\begin{aligned}
& W 3\left(\omega_{s}, S_{f s}\right)=57.238+1.23 \omega_{s}-1.745 S_{f s}+ \\
& +2.952 \omega_{s}^{2}+2.146 S_{f s}^{2}+0.199 \omega_{s} S_{f s}
\end{aligned}
$$

The change in humidity from the frequency and amplitude of the rotor oscillations.

$$
\begin{aligned}
& W 4\left(A_{o}, \omega_{s}\right)=57.238+0.205 A_{o}-0.983 \omega_{s}+ \\
& +3.346 A_{o}^{2}+3.429 \omega_{o}^{2}+0.139 \omega_{o} A_{o}
\end{aligned}
$$

The change in humidity from the rotor oscillations amplitude and the area of the free feed section.

$$
\begin{aligned}
& W 5\left(A_{o}, S_{f s}\right)=57.238+0.205 A_{o}-1.745 S_{f s}+ \\
& +3.346 A_{o}^{2}+2.146 S_{f s}^{2}+0.165 S_{f s} A_{o}
\end{aligned}
$$

The change in humidity from the rotor oscillations frequency and the area of the free feed section.

$$
\begin{aligned}
& W 6\left(\omega_{o}, S_{f s}\right)=57.238+0.983 \omega_{o}-1.745 S_{f s}+ \\
& +3.429 \omega_{o}^{2}+2.146 S_{f s}^{2}+0.084 \omega_{o} A_{o} S_{f s}
\end{aligned}
$$




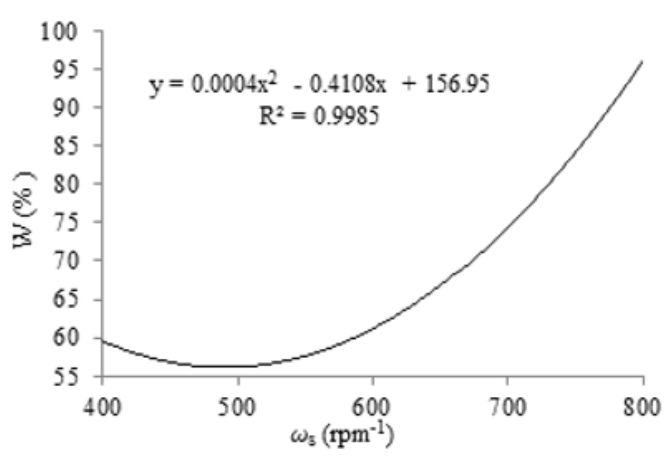

Fig. 3. Dependence of humidity change W (\%) on rotational speed of rotor centrifuge $\omega_{s}\left(\mathrm{rpm}^{-1}\right)$.

As it can be seen from the graph (Fig.3), at fixed vibration parameters with increasing rotor speed, the humidity of brewer pellets decreases to a minimum at 500 $\mathrm{rpm}^{-1}$ and then begins to increase. In the regime of sufficient loads, with an increase in the rotor speed to 500 $\mathrm{rpm}^{-1}$, which simultaneously performs axial oscillations, intensive sludge dewatering and an increase in the permeability of the liquid fraction of brewer pellets are observed [19, 20].

Based on the obtained data (21-27), the response surfaces and Fig. 3, it can be concluded that the parameters $\omega_{s}$ (rotor speed) and $S_{f s}$ (the area of the free feed section) have the greatest influence on the filtration process, and the vibration parameters $A_{o}$ (rotor oscillations amplitude) and $\omega_{o}$ (rotor oscillations frequency) also significantly influence this process, but to a lesser extent.

The regression Eq. (21) has an extremum (min) and coordinates, which can be used to determine the rational parameters of the installation: $\omega_{s}=500 \mathrm{~min}^{-1} ; A_{o}=4 \mathrm{~mm}$; $\omega_{o}=600 \mathrm{rpm}^{-1} ; S_{f s}=0.00072 \mathrm{~m}^{2}$, at which the humidity of brewer pellets is minimal and is $56-58 \%$.

Production tests were carried out on a simulated specimen of the vibratory-centrifugal centrifuge of a filtering type with optimal parameters, which showed a high quality of the separation of brewer pellets at a specific power consumption of the process and a productivity of 3.3 solid particles ${ }^{-1}$.

\section{Conclusion}

The second-order nonlinear multiple regression equation was obtained, which is a mathematical model of the dependence of the brewer pellets sludge humidity content on the basic parameters of the vibratory-centrifugal installation, which determines its rational parameters: rotor speed $\omega_{s}=500 \mathrm{rpm}^{-1}$; rotor oscillations amplitude $A_{o}=4 \mathrm{~mm}$; rotor oscillations frequency $\omega_{o}=600 \mathrm{rpm}^{-1}$; the area of the free feed section $S_{f s}=0.00072 \mathrm{~m}^{2}$, at which the humidity content of brewer pellets is minimal and is 56-58\%.

Improving the efficiency of the process and the service life of the device is achieved through the use of differentiation (distribution) of the liquid stream during the separation of brewer pellets into the liquid and dense fractions and providing on this basis an equi-thickened layer of the filtered material over the entire surface of the rotor blades with axial oscillations, besides, reversible rotor motion allows increasing filtration efficiency.

\section{References}

1. E. Väljaots, X. Lehiste, M. Kiik, T. Leemet, Agric. Res., 16, 3 (2018)

2. S.D. Ekanayake, D.S. Liyanapathirana, C.J. Leo, Soil Dyn. and Earth. Eng., 67 (2014)

3. V. Karpov, T. Kabanen, Iss. Agron. Res., 16, S1 (2018)

4. Z. Ben Salem, W. Frikha, M. Bouassida, Int. J. of Geomech., 16, 2 (2016)

5. I.Ya. Fedorenko, V.V. Sadov, Resource-Saving technologies and equipment in animal husbandry (Lan, Saint Petersburg, 2012)

6. J. Wannenmacher, M. Gastl, T. Becker, Compreh. Rev. in Food Sci. and Food Safety, 17, 4 (2018)

7. Z. Konrád, J. Los, J. Fryč, J. Kudělka, Res. Agr. Eng., 60 (2014)

8. P. Kosin, T. Branyik, J. Savel, F. Ulmann, J. Vlcek, J. of the Amer. Soc. of Brewing Chemists, 76, 1 (2018)

9. K. Spalvins, K. Ivanovs, D. Blumberga, Agron. Res., 16, S2 (2018)

10. N. Rettberg, M. Biendl, L.-A. Garbe, A rev. J. of the Amer. Society of Brewing Chemists, 76, 1 (2018)

11. M. S. Ahmetvaliev, Agr. and Ind. Com. of Russia (2015)

12. A.V. Litash, V.N. Nikolaev, M.S. Akhmetvaliev, Proc. of the IX Int. Sci.-pract. Conf. (2015)

13. V.P. Kovalenko, The mechanization of the processing liquid manure (Ear, 1984)

14. Device for dewatering of brewer's grains: Pat. 157095 Russian Federation. No. 2015129920; statement 20.07.2015; publ. 20.11.2015, bul. No. 326.

15. M.S. Ahmetvaliev, V.N. Nikolaev, E.V. Fetisov, Int. Sci.-pract. Conf., devoted to 110-anniver. from birthday of doctor of veter. Sci., Prof. Estina Alexander Vasilyevich (2016)

16. G.A. Okunev, S.D. Shepelev, S.P. Marinin, Design Engineering and Organization of Machine Use in Agriculture (South Ural State Agrar. Univer., Chelyabinsk, 2015)

17. L. Šenfelde, D. Kairiša, Agron. Res., 16, 3 (2018)

18. C. Hariprasad, M. Rajashekhar, B. Umashankar, Geotech. and Geolog. Eng., 34, 6 (2016)

19. A. Zeybek, S.P.G. Madabhushi, Soil Dyn. and Earth. Eng., 97 (2017)

20. A.I. Zavrazhnova, Modern problems of science and production in agricultural engineering (Lan, Saint Petersburg, 2013) 